\title{
Improving performance of DF Induction Generator SMES
}

\author{
Ayesha Sarosh ${ }^{1}$ M.Sudhakar ${ }^{2}$, M.Shankar ${ }^{3}$ \\ ${ }^{l}$ (EEE, Gitam University, Hyderabad, INDIA) \\ ${ }^{2}$ (EEE, KITS/JNTU, Khammam, INDIA) \\ ${ }^{3}(E E E$, KITS/JNTU, Khammam, INDIA
}

\begin{abstract}
Using of renewable energy sources are became very popular in the decade. One of the important renewable energy sources wind power generation has increased widely. Wind generators consist of double fed induction generator (DFIG). In this paper DFIG uses superconducting magnetic energy storage (SMES) unit for improving its performance. The converter and the chopper of the SMES unit are controlled using a hysteresis current controller and a fuzzy logic controller, respectively. Simulation carried out using MATLAB/SIMULINK software to track SMES unit in improving performance of DFIG under voltage sag and swell conditions.
\end{abstract}

\section{Introduction}

Utilization of renewable energy sources is becoming more attractive due to the detrimental impact of more attractive due to the detrimental impact of conventional energy resources on the environment. Implementation of carbon tax in some countries has also been considered as a trigger to accelerate the utilization of renewable energy sources [1]. One of the most promising renewable energy sources is wind energy, which has grown rapidly from about 2000 MW at the end of the year 1990 to 94000 MW by the end of the year 2007. The future prospects of the global wind industry are very encouraging, and it is estimated to grow by more than $70 \%$ to reach $160 \mathrm{GW}$ by the year 2012. It is estimated that, by the year 2020 , wind power will supply at least $10 \%$ of global electricity demands [2]. Owing to the rapid development of power electronics technology, the number of wind turbines equipped with converter stations has increased. The doubly fed induction generator (DFIG) is one of the most popular variable speed wind turbine generators (WTGs). In this technology, the rotor winding is connected to a coupling transformer through a back-to-back partial-scale voltage source converter (VSC), whereas the stator winding is directly connected to the grid at a point of common coupling (PCC) through the coupling transformer. The VSC decouples the mechanical and electrical frequencies and make variable-speed operation possible [3]. Global trend shows that the market share of the installed wind energy conversion system (WECS) has been dominated by DFIG-based wind turbines since 2002 [4]. In the earlier stages of integrating WECSs into the electricity grids, WTGs were disconnected from the grid during faults at the grid side to avoid any possible damages to wind turbines. Recently, existing WTGs, however, will have to be designed/ managed to comply with the recent requirements of new grid codes [5] to assure the continuity of supplying power to the grid during transient and abnormal operating conditions. There are two strategies that can be applied to improve the performance or the fault ride through (FRT) capability of the DFIG. First is by developing new control techniques to fulfil the criterion of the transmission system operators, as presented in most of the literature [6]-[10]. However, this strategy is effective for new installation and new connection of WECSs to the grid. Second is by applying FACTS devices or storage energy systems [11], which are a more cost effective choice for existing WECSs. Variable speed WECSs such as DFIG were introduced to overcome the weakness of the fixed-speed type in capturing maximum wind energy and to contribute in supplying reactive power to the grid when required [12]. Compared with full-scale variable speed WECSs, DFIG is very sensitive to grid faults [7], where, even though the DFIGs are connected far away from the grid, the grid faults will influence the voltage profile at the PCC. Moreover, during grid fault, voltage drop at the DFIG terminal, high current flow at both grid and rotor side converters, and high voltage across the dc link capacitor may lead to converter station blocking. This condition will be ended by the disconnection of the DFIG from the system. If the DFIG contributes in delivering a large portion of power to the grid, financial loss will be uncountable. Most of the studies about the DFIG are concerned about the improvement of its FRT capability during voltage sag [6]-[10]. No attention however is given to improve the DFIG performance under voltage sag and voltage swell conditions using the same controller. Although the swell event in the grid side is rarely to occur, it can cause voltage rise at the PCC that may violate the grid codes' requirements. Recently, the maximum voltage ride through of Spain [13] and Australia's [14] grid codes is set to $1.3 \mathrm{pu}$. If the voltage profile at the PCC rises above $1.3 \mathrm{pu}$, the WTGs have to be disconnected from the grid. Since the successful installation of the 30-MJ superconducting magnetic energy storage (SMES) unit at Bonneville power administration, Tacoma, in 1982 [15], SMES has attracted many researchers to study its potential applications in power systems [16]-[18]. 


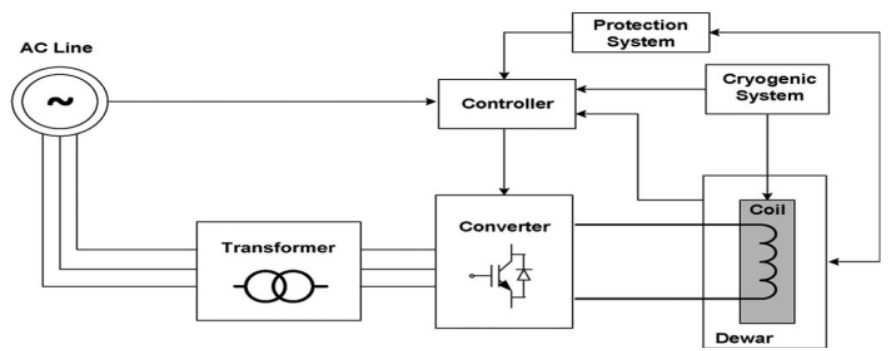

Fig. 1. Typical schematic diagram of an SMES unit.

There are many papers in the literature that investigated the application of SMES to WECSs. However, most of these studies have only focused on the use of the SMES unit to smooth the output power of fixed-speed WECSs during wind speed fluctuation to avoid system instability [19]-[26]. This paper presents a new application of the SMES unit to improve the performance of a wind turbine equipped with DFIG during voltage sag and voltage swell at the grid side. A new control system for the SMES unit based on hysteresis current control in conjunction with fuzzy logic control is proposed. The Simulink/Matlab software is used to simulate the wind turbine, the SMES unit, and the model under study. Results are analysed to highlight the improved dynamic performance of WECSs in conjunction with the SMES unit.

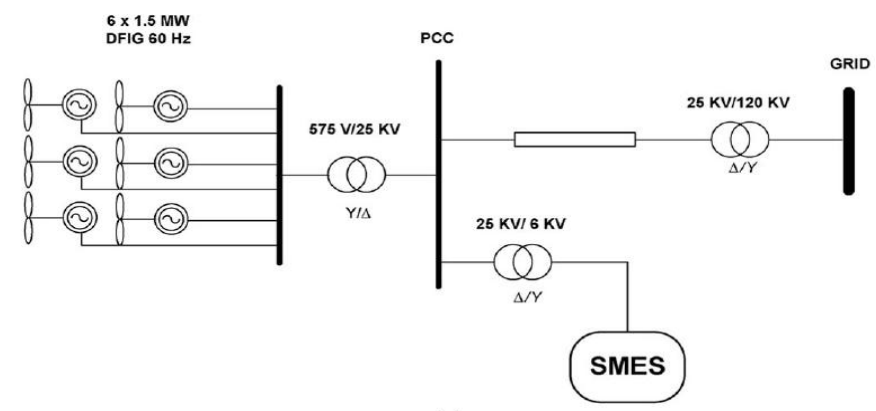

(a)

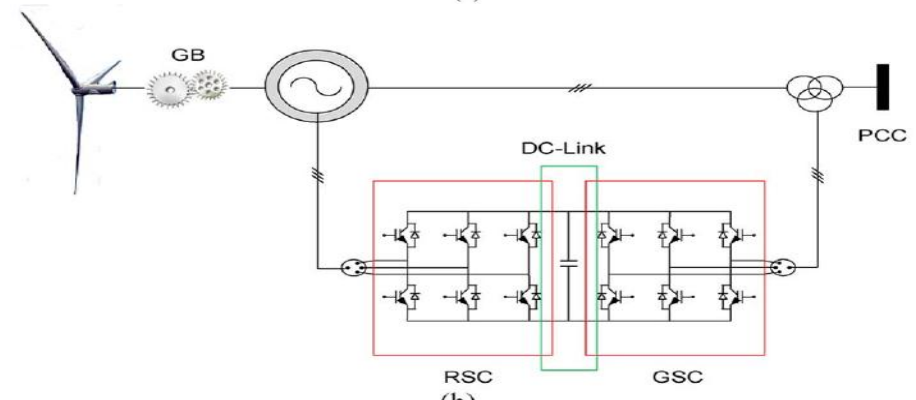

(b)

Fig. 2. (a) System under study. (b) Typical configuration of an individual DFIG.

\section{Smes}

An SMES system consists of a superconductor coil, a power-conditioning system, a cryogenic refrigerator, and a cryostat/vacuum vessel to keep the coil at a low temperature required maintaining it in superconducting state. This configuration makes SMES highly efficient in storing electricity with typical efficiency in the range of 95\%-98\% [27]-[29]. Other advantages of the SMES unit include very quick response and possibilities for high-power applications [30]. A typical SMES configuration is shown in Fig. 1.

\section{System Under Study}

The system under study shown in Fig. 2(a) consists of six 1.5-MW DFIGs connected to the ac grid at the PCC. The DFIG consists of an induction generator with stator winding connected directly to the grid through a $Y / \Delta$ step-up transformer, whereas the rotor winding is connected to a bidirectional back-to-back insulated gate bipolar transistor (IGBT) VSC, as shown in Fig. 2(b). The grid that is represented by an ideal three-phase voltage source of constant frequency is connected to the wind turbines via a $30-\mathrm{km}$ transmission line and $\Delta / \mathrm{Y}$ step-up transformer. The reactive power produced by the wind turbines is regulated at zero MVar under normal operating conditions. For an average wind speed of $15 \mathrm{~m} / \mathrm{s}$, which is used in this study, the turbine output power is $1.0 \mathrm{pu}$, and the generator speed is $1.2 \mathrm{pu}$. The SMES unit is connected to the $25-\mathrm{kV}$ bus and is assumed to be fully charged at its maximum capacity of 1.0 MJ Tables I and II. 


\begin{tabular}{|c|c|}
\hline Duty Cycle (D) & SMES Coil Action \\
\hline $\mathrm{D}=0.5$ & Standby condition \\
\hline $0 \leq \mathrm{D} \leq 0.5$ & Discharging condition \\
\hline $0.5<\mathrm{D} \leq 1$ & Charging condition \\
\hline
\end{tabular}

Table 1: Parameters of the DFIG

\begin{tabular}{|c|c|}
\hline Rated Power & $9 \mathrm{MW}(6 \mathrm{x} @ 1.5 \mathrm{MW})$ \\
\hline Stator Voltage & $575 \mathrm{~V}$ \\
\hline Frequency & $60 \mathrm{~Hz}$ \\
\hline $\mathrm{R}_{\mathrm{s}}$ & $0.023 \mathrm{pu}$ \\
\hline $\mathrm{R}_{\mathrm{R}}$ & $0.016 \mathrm{pu}$ \\
\hline $\mathrm{V}_{\mathrm{DC}}$ & $1150 \mathrm{~V}$ \\
\hline
\end{tabular}

Table 2: Parameters of the Transmission Line

\section{Smes Control Approaches}

Generally, there are two major configurations of SMES, i.e., current source converter (CSC) and VSC. Traditionally, CSC is connected through a 12-pulse converter configuration to eliminate the ac-side fifth and seventh harmonic currents and the dc side sixth harmonic voltage, thus resulting in significant savings in harmonic filters [18]. However, because this configuration uses two 6-pulse CSCs that are connected in parallel, its cost is relatively high. The VSC, on the other hand, must be connected with a dc-dc chopper through a dc link, which facilitates energy exchange between the SMES coil and the ac grid. Reference [31] estimates the total cost of the switching devices of the CSC to be $173 \%$ of the switching devices and power diodes required for equivalent capacity of the VSC and the chopper. Moreover, a VSC has a better self-commutating capability, and it injects lower harmonic currents into the ac grid than a comparable CSC. The use of IGBTs in this configuration is more beneficial than GTO since the switching frequency of an IGBT lies on the range of 2-20 $\mathrm{kHz}$, whereas, in case of GTO, the switching frequency cannot exceed $1 \mathrm{kHz}$ [4]. The proposed SMES configuration used in this paper consists of a VSC and dc-dc chopper, as shown in Fig. 3. The converter and the chopper are controlled using a hysteresis current controller (HCC) and a fuzzy logic controller (FLC), respectively. The stored energy in the SMES coil can be calculated as

$$
E=\frac{1}{2} I^{2}{ }_{S M E S} L_{S M E S}
$$

Where E, ISMES, and LSMES are the stored energy, current, and coil inductance of the SMES unit, respectively. While the control system of the dc-dc chopper is presented in [32], the control approach for the VSC as part of the SMES configuration is not presented. In contrast with [32], the dc-dc chopper control system

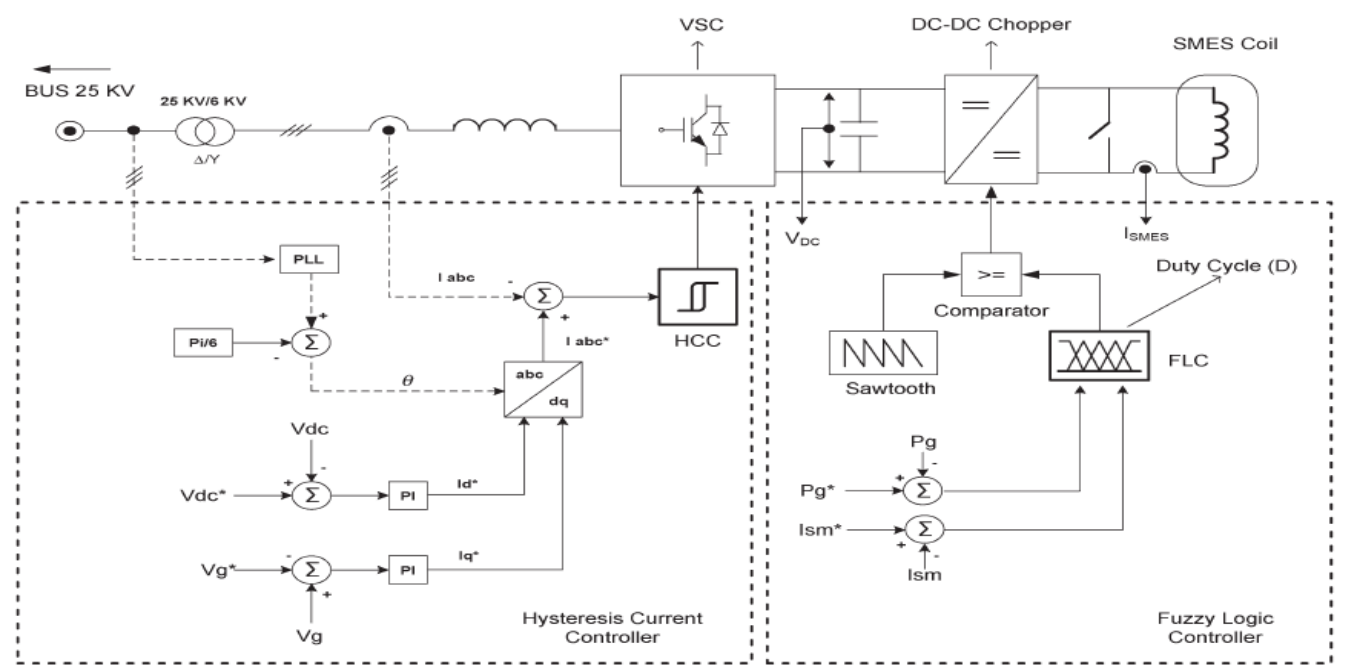

Fig. 3. SMES unit configuration and the proposed HCC-FLC control scheme.

is not presented in [19]. The configuration of SMES in [33] is new, but its application is limited for low WTG capacity, and since the SMES coil is proposed to be connected to the individual DFIG's converters, this topology will be only appropriate for new WECS installations. Application of the SMES system to micro grids is presented in [34], where the SMES is used to stabilize the entire micro grid system. The control scheme presented in this work is very complex because it is working for three different levels of controls; this will lead to high implementation and maintenance cost. Moreover, it requires a robust computational system. The proposed control algorithm in this paper is much simpler and closer to realistic applications, compared with the similar controller proposed in [16] and [21]. In the aforementioned papers, four proportional-integral (PI) 
controllers are proposed, which require more computational time to optimally tune its parameters to maintain overall system stability and to achieve satisfactory dynamic response during transient events. Moreover, the control system for the dc-dc chopper in these studies considered only the DFIG-generated active power (PG) as a control parameter, but it ignored the energy capacity of the SMES unit. The control scheme in this paper comprises only two PI controllers and considers the SMES coil current to take the SMES stored energy capacity into account, along with the DFIG generated power as control parameters to determine the direction and level of power exchange between the SMES coil and the ac system. This control system is efficient, simple, and easy to implement, as will be elaborated here.

\section{A. Hcc}

The HCC is widely used because of its simplicity, insensitivity to load parameter variations, fast dynamic response, and inherent maximum-current-limiting characteristic [35]. The basic implementation of the $\mathrm{HCC}$ is based on deriving the switching signals from the comparison of the actual phase current with a fixed tolerance band around the reference current associated with that phase. However, this type of band control is not only depending on the corresponding phase voltage but is also affected by the voltage of the other two phases [36].

The effect of interference between phases (referred to as inter phase dependence) can lead to high switching frequencies. To maintain the advantages of the hysteresis methods, this phase dependence can be minimized by using the phase-locked loop (PLL) technique to maintain the converter switching at a fixed predetermined frequency level [37]. The proposed SMES with an auxiliary PLL controller is shown in Fig. 3. The HCC is comparing the three-phase line currents (Iabc) with the reference currents (I* abc), which is dictated by the $I * d$ and $I * q$ references. The values of $I * d$ and $I * q$ are generated through conventional PI controllers based on the error values of Vdc and Vs.

The value of $\mathrm{I} * \mathrm{~d}$ and $\mathrm{I} * \mathrm{q}$ is converted through Park transformation $(\mathrm{dq} 0-\mathrm{abc})$ to produce the reference current range of the SMES coil.

Fig. 4. Structure of the proposed fuzzy controller.

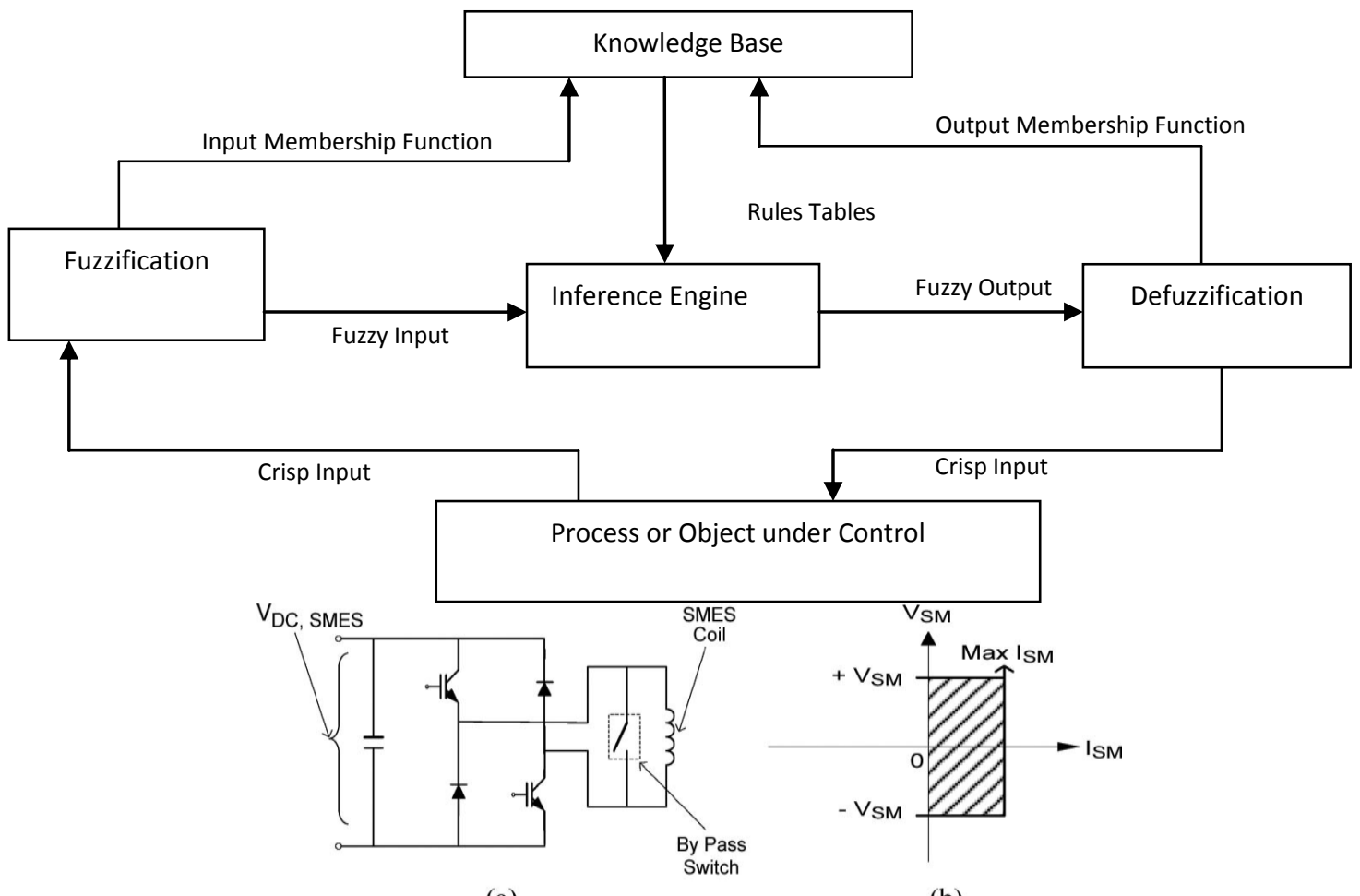

(a)

(b)

Fig. 5. (a) Class-D dc-dc chopper topology with an SMES coil. (b) Operation range of the SMES coil.

B. $F l c$

To control power transfer between the SMES coil and the ac system, a dc-dc chopper is used, and fuzzy logic is selected to control its duty cycle (D), as shown in Fig. 3. The FLC is developed according to the fuzzy inference flowchart shown in Fig. 4, which is a process of formulating the mapping from a given input to the designated output. Input variables for the model are the real power generated by the DFIG and the SMES coil current. The output of the FLC is the duty cycle (D) for a class-D dc-dc chopper that is shown in Fig. 5(a). The V -I 
operational range for the SMES coil is shown in Fig 5(b). The duty cycle determines the direction and the magnitude of the power exchange between the SMES coil and the ac system, as presented in Table III.

If the duty cycle (D) is equal to 0.5 , no action will be taken by the coil, and the system is under normal operating conditions. Under this condition, a bypass switch that is installed across the SMES coil [shown in Fig. 5(a)] will be closed to avoid the draining process of SMES energy during normal operating conditions. The bypass switch is controlled in such a way that it will be closed if $\mathrm{D}$ is equal to 0.5 ; otherwise, it will be opened. This technique has been introduced in some studies in the literature [21], [31]. When the grid power is reduced, D will be reduced accordingly to be in the range of $0-0.5$, and the stored energy in the SMES coil will be transferred to the ac system. The charging process of the SMES coil takes place when D is in the range of $0.5-1$. The relation between VSMES and VDC, SMES can be written as [31]

\begin{tabular}{|c|c|}
\hline $\mathrm{R}_{1}, \mathrm{R}_{0}(\Omega / \mathrm{km})$ & $0.1153,0.413$ \\
\hline $\mathrm{L}_{1}, \mathrm{~L}_{0}(\mathrm{H} / \mathrm{km})$ & $1.05 \times 10^{-3}, 3.32 \times 10^{-3}$ \\
\hline $\mathrm{C}_{1}, \mathrm{C}_{0}(\mathrm{~F} / \mathrm{km})$ & $11.33 \times 10^{-9}, 5.01 \times 10^{-9}$ \\
\hline
\end{tabular}

TABLE III RULES OF THE DUTY CYCLE

$$
V_{\text {SNES }}=(1-2 D) V_{D C, \text { SNES }}
$$

Where VSMES is the average voltage across the SMES coil, D

is duty cycle, and VDC,SMES is the average voltage across the dc-link capacitor of the SMES configuration. The model is built up using the graphical user interface tool provided by MATLAB. Each input was fuzzified into five sets of Gaussmf-type membership function (MF). The Gaussian curve is a function of a vector $\mathrm{x}$ and depends on parameters $\sigma$ and $\mathrm{c}$, as given by

$$
f\left(x_{j}, \sigma_{y} c\right)=e^{-(x-c)^{2} / 2 \sigma^{2}}
$$

where $\sigma$ and $\mathrm{c}$ are the variables that determine the center of the peak and the width of the bell curve, respectively. The corresponding MFs for the input variables PG and ISMES are shown in Figs. 6 and 7, respectively. The MFs for the output variable (duty cycle) are considered on the scale of 0 to 1 , as shown in Fig. 8. Center of gravity, which is widely used in fuzzy models, is used for the defuzzification process, where the desired output $\mathrm{z} 0$ is calculated as [38]

$$
Z_{0}=\frac{\int z \cdot \mu_{d}(z) d z}{\int \mathbb{H}_{d}(z) d z}
$$

where $\mu \mathrm{c}(\mathrm{z})$ is the MF of the output. The variation range in the SMES current and DFIG output power, as well as the corresponding duty cycle, is used to develop a set of fuzzy logic rules in the form of (IF-AND-THEN) statements to relate the input variables to the output.

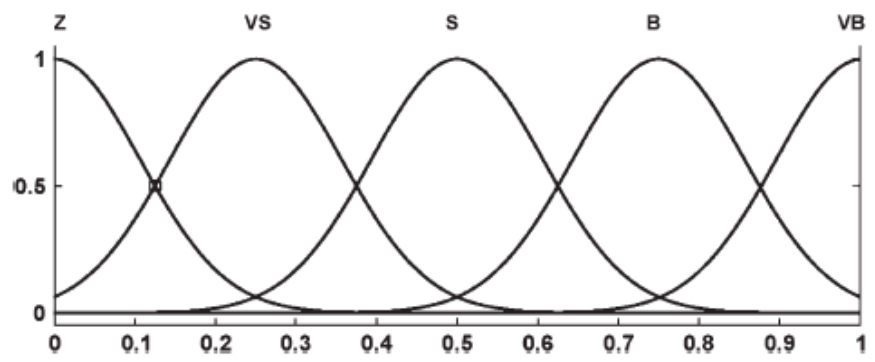

Fig. 7. MF for the input variable ISMES (pu).

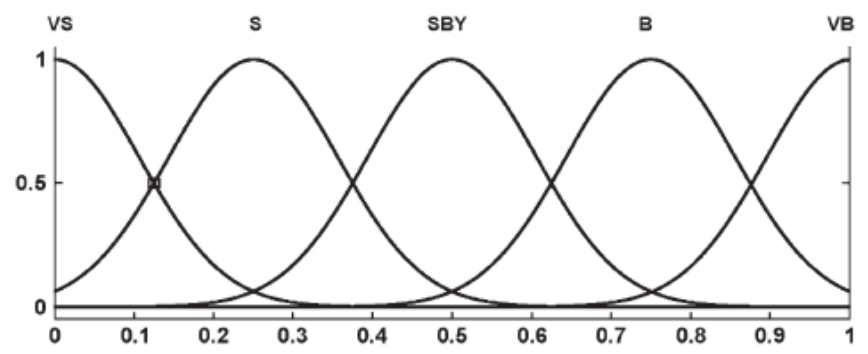

Fig. 8. MF for the output variable $D$ (duty cycle). 


\section{A. Voltage Sag Event}

\section{Simulation Results And Discussion}

A voltage sag depth of 0.5 pu lasting for $0.05 \mathrm{~s}$ is applied at $\mathrm{t}=2 \mathrm{~s}$ at the grid side of the system under study [Fig. 2(a)]. Without the SMES unit, the real power produced by the DFIG will drop to $0.6 \mathrm{pu}$, and it reaches a maximum overshooting of $40 \%$ during the clearance of the fault, as shown in Fig 10(a). As can be seen in Fig 10(a), with the SMES unit connected to the system, the DFIG output power will drop to only 0.875 pu. Fig. 10(b) implies that, with the connection of the SMES unit and during the event of voltage sag, the reactive power support by the DFIG is reduced, and the steady-state condition is reached faster, compared to the system without SMES. The voltage at the PCC is shown in Fig. 10(c), where without SMES, voltage will drop to $0.6 \mathrm{pu}$. However, by connecting the SMES unit, voltage drop at the PCC will be reduced to only $0.8 \mathrm{pu}$, which will lead to a voltage drop at the generator terminal to a level of $0.8 \mathrm{pu}$, which is referenced

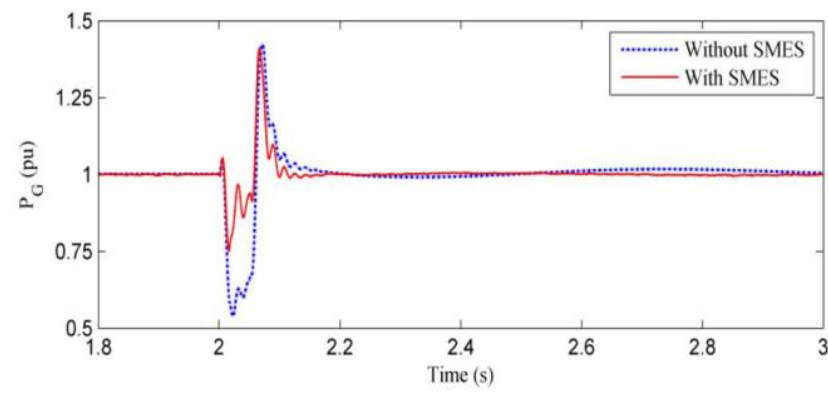

(a)

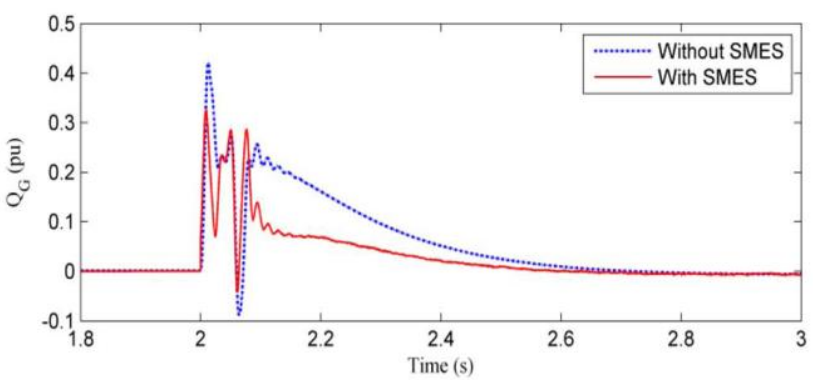

(b)

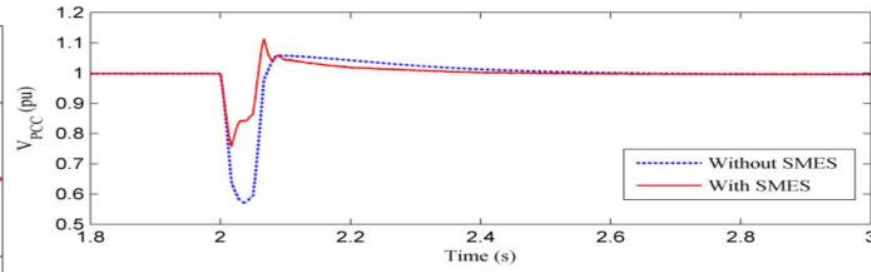

(c)

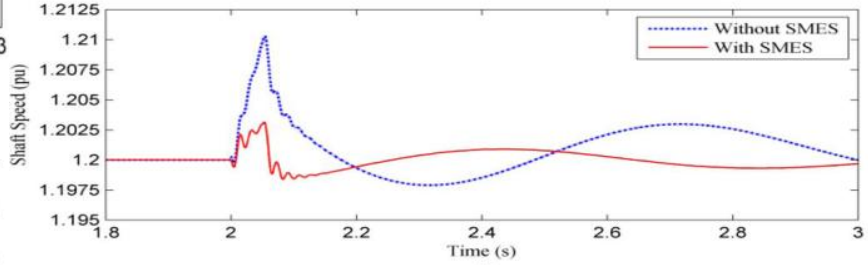

(d)

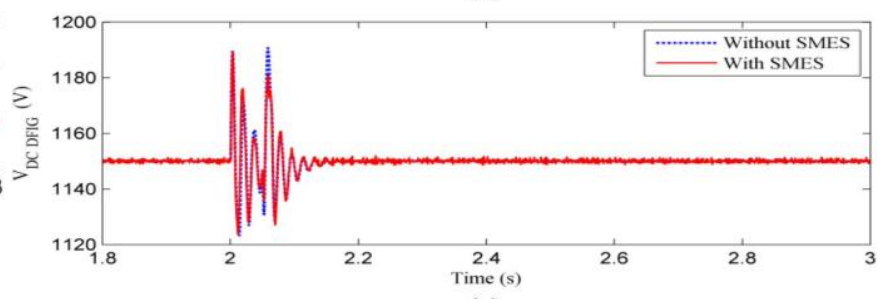

(e)

Fig. 10. DFIG responses during voltage sag without/with an SMES unit. (a) Active power. (b) Reactive power. (c) PCC voltage. (d) Shaft speed. (e) Voltage at the dc-link of the DFIG.

SMES. The voltage at the PCC is shown in Fig. 10(c), where without SMES, voltage will drop to $0.6 \mathrm{pu}$. However, by connecting the SMES unit, voltage drop at the PCC will be reduced to only 0.8 pu, which will lead to a voltage drop at the generator terminal to a level of $0.8 \mathrm{pu}$, which is referenced as safety margin by the wind turbine manufacturers [39]. The DFIG power drop causes the generator speed to be accelerated to compensate for the power imbalance. As can be observed in Fig. 10(d), the generator speed will accelerate and oscillate without the SMES unit; however, with the SMES connected to the system, the power drop is reduced, the settling time of the generator speed is substantially reduced, and the overshooting level is significantly decreased. Another effect of the voltage sag on the DFIG's behavior is on the voltage across the DFIG dc link capacitor that is shown in Fig. 10(e). The voltage overshoot across the dc-link capacitor during fault clearance is slightly reduced with the SMES unit connected to the system.

\section{B. Voltage Swell Event}

Voltage swell can occur due to switching off a large load or switching on a large capacitor bank. In this simulation, a voltage swell is applied by increasing the voltage level at the grid side to $1.5 \mathrm{pu}$. The voltage swell is assumed to start at $\mathrm{t}=2 \mathrm{~s}$ and lasts for $0.05 \mathrm{~s}$. In this event, the DFIG-generated power will increase upon the swell occurrence and will be reduced when it is cleared, as shown in Fig. 11(a). The maximum power overshoot is slightly reduced with the SMES unit connected to the system. To compensate for the voltage rise, DFIG will absorb the surplus reactive power, as shown in Fig. 11(b). The amount of reactive power absorbed by the DFIG is lesser with SMES connected to the PCC since the voltage profile at the PCC is rectified to a level below 1.3 pu with the connection of the SMES unit, whereas this voltage will remain above 1.3 pu without SMES connected to the PCC [Fig. 11(c)]. Without the connection of the SMES unit, the voltage at the PCC does not 
comply with the high voltage ride through (HVRT) of Spain and Australia grid codes [13], [14], which will lead to the disconnection of the DFIG from the system. The shaft speed [shown in Fig. 11(d)] is slightly improved with the connection of the SMES unit to the system.

Without the connection of the SMES unit, the voltage across the DFIG dc-link capacitor will experience significant oscillations and overshooting level upon voltage swell incidence, as can be shown in Fig. 11(e). In some occasions, this may lead to the blocking of the converters [39]. As shown in Fig. 11(e), voltage oscillations, as well as voltage overshooting level, are significantly reduced by connecting the SMES unit to the system.
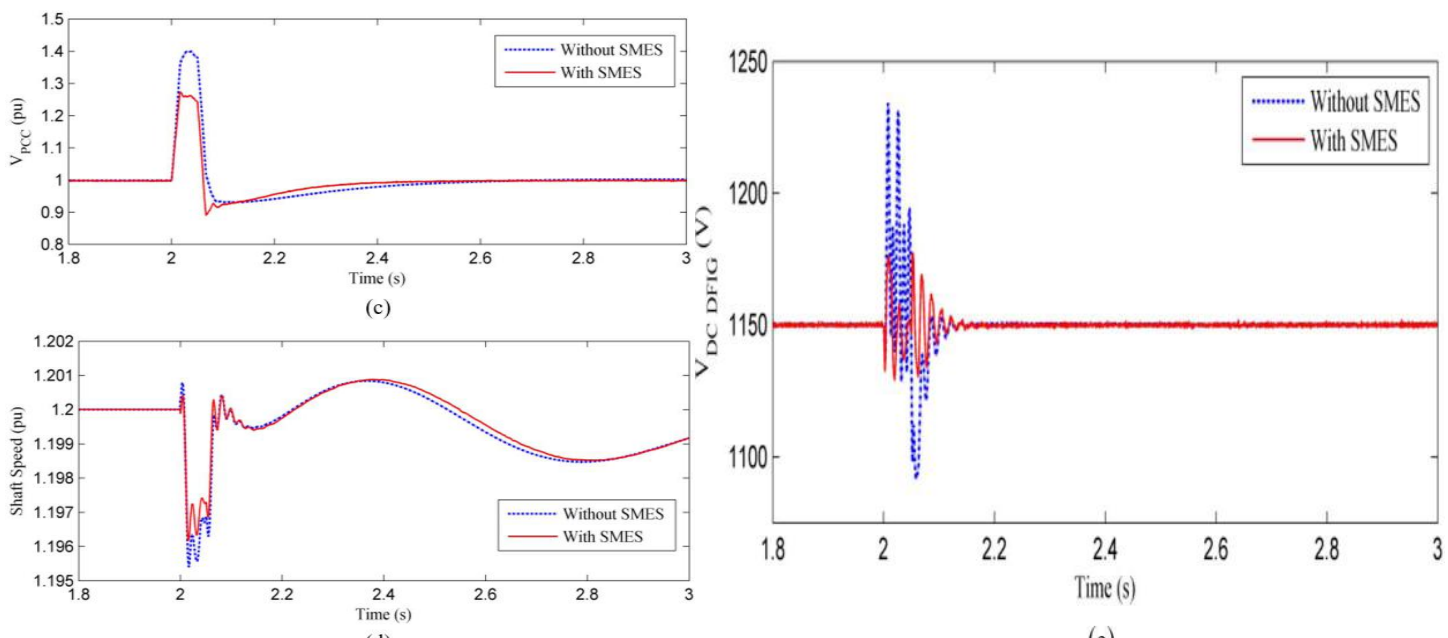

(e)

Fig. 11. DFIG responses during voltage swell without/with an SMES unit. (a) Active power. (b) Reactive power. (c) PCC voltage. (d) Shaft speed. (e) Voltage at the dc-link of the DFIG.

\section{Smes Responses During Voltage Sag And Swell}

The current ISMES passing through the superconducting inductor is unidirectional; however, the voltage VSMES across the inductor terminals can be varied in a wide range between positive and negative values through the control of the duty cycle of the dc-dc chopper (D); thus, reversibility, as well as magnitude control of power flow, is achieved continuously and smoothly through the control of the duty cycle. There are three operation modes of the SMES unit.

1) Standby mode occurs when D is equal to 0.5 . The voltage across the SMES coil is equal to zero, and the SMES coil current is held constant at its rated value (2 kA for the SMES unit under study); consequently, there will be no energy transferred between the SMES unit and the AC system, and maximum energy ( $1 \mathrm{MJ}$ for the SMES unit under study) is stored within the superconductor coil. The voltage across the dc-link capacitor of the SMES configuration (VDC, SMES) is maintained at a constant level of $10 \mathrm{kV}$ during this mode of operation. This mode will take place during normal operating condition of the WECS and is shown in Fig. 12 prior and after the occurrence of the fault.

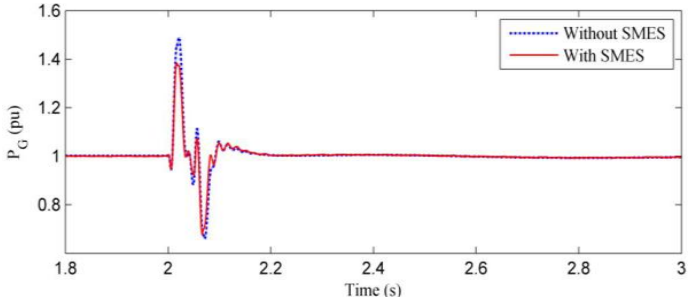

(a)

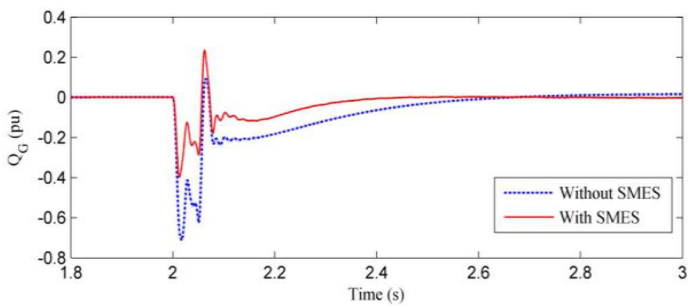

(b)
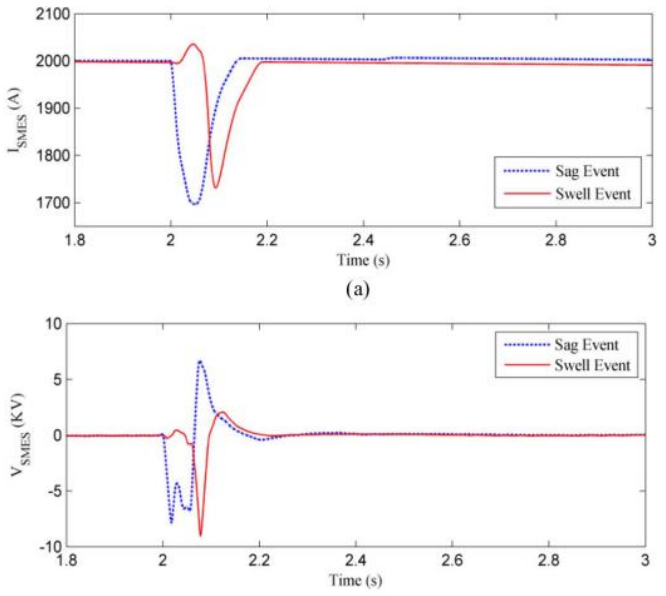

Fig. 12. SMES transient responses during voltage sag and swell including (a) stored energy, 


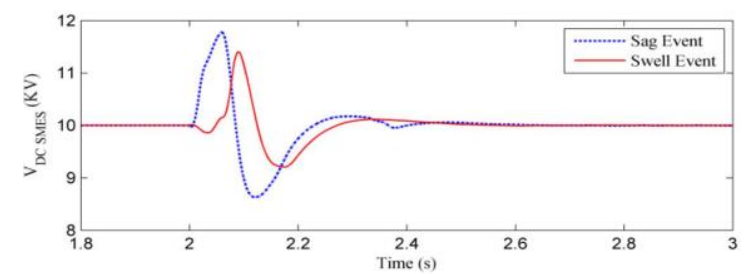

(e)

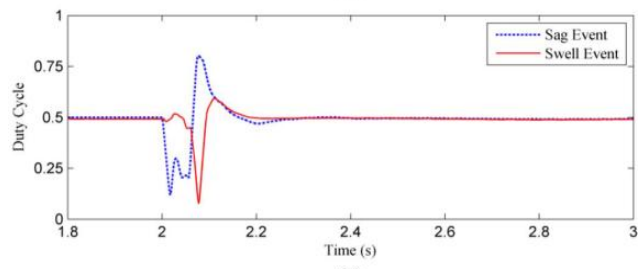

(c)

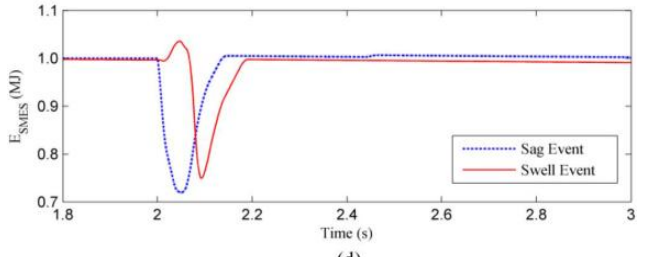

(d)

(b) current, (c)

voltage, (d) duty cycle, and (e) voltage at the dc-link of the SMES.

2) Discharging mode will take place when voltage sag disturbance occurs at the grid side. In this case, the value of $\mathrm{D}$ lies in the range of $0-0.5$. When voltage sag occurs at $\mathrm{t}=2 \mathrm{~s}$, the SMES coil current decreases, giving a negative slope (di/dt), and consequently, the voltage across the coil is turning negative. The magnitude of the voltage across the SMES coil is controlled by the level of the duty cycle, as well as the voltage across the SMES dc-link capacitor as given in (2). The energy stored in the coil is being delivered to the AC system during this mode, and the coil will be recharged at $\mathrm{t}=2.05 \mathrm{~s}$, exactly at the time when the fault is cleared according to the rules of the designated FLC for PG and ISMES. During discharging mode, the rate of coil current change is decided by the level of the duty cycle. It is observed that the SMES voltage VSMES responds rapidly, and the transfer of SMES energy is done immediately upon the occurrence of voltage sag at $t=2 \mathrm{~s}$. This mode of operation is shown by the dashed plots in Fig. 12 during the period $t=2 \mathrm{~s}$ to $\mathrm{t}=2.2 \mathrm{~s}$.

3) Charging mode will take place when voltage swell disturbance occurs at the grid side. In this case, the value of $\mathrm{D}$ lies in the range of $0.5-1$. When voltage swell occurs at $\mathrm{t}=2 \mathrm{~s}$, the SMES coil current increases, giving a positive slope (di/dt), and consequently, the voltage across the coil is turning positive. The energy is transferred from the system to the SMES coil until the maximum coil energy capacity designated by the fuzzy rules is reached (1.03 MJ in the system under study to allow for power modulation during voltage swell disturbance) after which the voltage across the SMES coil decreases and returns back to zero level when the maximum current in the SMES coil is reached. This mode of operation is shown by the solid plots in Fig. 12 during the period $\mathrm{t}=2 \mathrm{~s}$ to $\mathrm{t}=2.2 \mathrm{~s}$.

The following general observations can be concluded. It can be observed that the SMES coil current in both voltage sag and voltage swell events has a similar trend to the coil stored energy and their levels at any time are mathematically correlated by the relation given in (1). In both voltage sag and voltage swell events, voltage across the SMES coil will be maintained at zero level once the maximum current in the SMES coil is reached. Once a system with SMES unit has regained post fault stability, the SMES coil is not preferred to be kept on continuously to avoid the draining process of SMES energy during normal operating conditions. Furthermore, turning it off can reduce the generator shaft speed oscillations to some extent. It also reduces the operating expenses of the SMES unit. This is achieved by short circuiting the SMES coil through a bypass switch shown in Fig. 5(a).

In both the voltage sag and voltage swell events, it is observed that the voltage across the dc-link capacitor of the SMES configuration (VDC,SMES) oscillates in an opposite manner to VSMES, and its level at any time is related to the level of VSMES. The level of VSMES at any time is correlated to the level of VDC,SMES and the duty cycle value by the relation given in (2).

\begin{tabular}{|c|c|}
\hline Rated Energy & $1.0 \mathrm{MJ}$ \\
\hline$L_{\text {SMES }}$ & $0.5 \mathrm{H}$ \\
\hline$I_{\text {SMES }}$ & $2000 \mathrm{~A}$ \\
\hline
\end{tabular}

Table IV Parameters of the SMES Unit

The maximum voltage overshoot in VDC,SMES shown in Fig. 12(d) still remains within a safety margin of 1.25 pu of the nominal value [39], which corresponds to $12 \mathrm{kV}$ in the studied case. It is also noted that the voltage across the SMES coil and the duty cycle have the same trend during the disturbance event. This aligns well with the results presented in [31].

D. Smes Capacity 
The SMES unit capacity depends on the application and charging/discharging duration. Very high energy rating has excellent impact on damping oscillations rapidly, but the cost of the unit will be too high due to large current in the coil. Meanwhile, if the energy rating is too low, the output of the SMES unit will be limited during disturbances, and it will not be very effective in controlling system oscillations quickly. The first SMES unit rated $30 \mathrm{MJ}$ with a rated coil current of $5 \mathrm{kA}$ was installed in Bonneville power administration, Tacoma, in 1982 [40]. An SMES coil energy ESMES of value less than 0.15 of the generator rated power will be adequate in safeguarding against momentary power interruption [17], [18]. In the system under study, the DFIG rated power is $9 \mathrm{MW}$, and the rated energy of the SMES coil is designed to be $1 \mathrm{MJ}$. As the SMES coil inductance is chosen to be $0.5 \mathrm{H}$, the inductor nominal current is $2 \mathrm{kA}$ (Table IV). To make the SMES coil effective in voltage swell events, the rated inductor current is set at a level higher than the nominal coil current [41]. In the system under study, the rated coil current was chosen to be $2.03 \mathrm{kA}$. This will allow the SMES coil to absorb maximum energy up to $1.03 \mathrm{MJ}$ during the voltage swell event.

\section{Conclusion}

A new control algorithm along with a new application of the SMES unit to improve the transient response of WTGs equipped with DIFG during voltage sag and voltage swell events has been proposed. Simulation results have shown that the SMES unit is very effective in improving the dynamic performance of a power system with wind turbine equipped with DFIG during voltage sag and voltage swell at the grid side.

The proposed control algorithm of the SMES unit is simple and easy to implement and is able to improve the FRT of the DFIG. The SMES unit, on the other hand is still a costly piece of equipment; however, due to the development of high temperature superconducting materials, its application in power systems is expected to become viable in the near future.

\section{References}

[1]. L. Freris and D. Infield, Renewable Energy in Power Systems. Wiltshire,U.K.: Wiley, 2008, p. 217.

[2]. P. Musgrove, Wind Power. New York: Cambridge Univ. Press, 2010, pp. 221-222.

[3]. J. M. Carrasco, L. G. Franquelo, J. T. Bialasiewicz, E. Galvan, R. C. P. Guisado, M. A. M. Prats, J. I. Leon, and N. MorenoAlfonso, "Power-electronic systems for the grid integration of renewable energy sources: A survey," IEEE Trans. Ind. Electron., vol. 53, no. 4, pp. 1002-1016, Jun. 2006.

[4]. T. Ackerman, Wind Power in Power System. West Sussex, U.K.: Wiley,2005, p. 65.

[5]. M. Tsili and S. Papathanassiou, "A review of grid code technical requirements for wind farms," IET Renew. Power Gener., vol. 3, no. 3, pp. 308-332, Sep. 2009.

[6]. S. Seman, J. Niiranen, and A. Arkkio, "Ride-through analysis of doubly fed induction wind-power generator under unsymmetrical network disturbance," IEEE Trans. Power Syst., vol. 21, no. 4, pp. 1782-1789, Nov. 2006.

[7]. J. Lopez, E. Gubia, E. Olea, J. Ruiz, and L. Marroyo, "Ride through of wind turbines with doubly fed induction generator under symmetrical voltage dips," IEEE Trans. Ind. Electron., vol. 56, no. 10, pp. 4246-4254, Oct. 2009.

[8]. M. Mohseni, S. M. Islam, and M. A. S. Masoum, "Impacts of symmetrical and asymmetrical voltage sags on DFIG-based wind turbines considering phase-angle jump, voltage recovery, and sag parameters," IEEE Trans. Power Electron., vol. 26, no. 5, pp. 1587-1598, May 2011.

[9]. Y. Xiangwu, G. Venkataramanan, P. S. Flannery, W. Yang, D. Qing, and Z. Bo, "Voltage-sag tolerance of DFIG wind turbine with a series grid side passive-impedance network," IEEE Trans. Energy Convers., vol. 25, no. 4, pp. 1048-1056, Dec. 2010.

[10]. S. Hu, X. Lin, Y. Kang, and X. Zou, "An improved low-voltage ridethrough control strategy of doubly fed induction generator during grid faults," IEEE Trans. Power Electron., vol. 26, no. 12, pp. 3653-3665, Dec. 2011.

[11]. J. G. Slootweg, S. W. H. de Haan, H. Polinder, and W. L. Kling, "General model for representing variable speed wind turbines in power system dynamics simulations," IEEE Trans. Power Syst., vol. 18, no. 1, pp. 144-151, Feb. 2003.

[12]. F. Blaabjerg and Z. Chen, Power Electronics for Modern Wind Turbines. Aalborg, Denmark: Morgan \& Claypool, 2006 , p. 18.

[13]. M. Altin, O. Goksu, R. Teodorescu, P. Rodriguez, B. B. Jensen, and L. Helle, "Overview of recent grid codes for wind power integration," in Proc. 12th Int. Conf. OPTIM, 2010, pp. 1152-1160.

[14]. AEMO. [Online]. Available: www.aemo.com.au

[15]. H. J. Boenig and J. F. Hauer, "Commissioning tests of the bonneville power administration 30 MJ superconducting magnetic energy storage unit,” IEEE Trans. Power App. Syst., vol. PAS-104, no. 2, pp. 302-312, Feb. 1985.

[16]. M. H. Ali,W. Bin, and R. A. Dougal, “An overview of SMES applications in power and energy systems," IEEE Trans. Sustainable Energy, vol. 1, no. 1, pp. 38-47, Apr. 2010.

[17]. A. Abu-Siada, "Application of superconducting magnetic energy storage units to improve power system performance," Ph.D. thesis, Dept. Elect. Eng., Curtin Univ. Technol., Bentley, Australia, 2004.

[18]. A. Abu-Siada and S. Islam, "Application of SMES unit in improving the performance of an AC/DC power system," IEEE Trans. Sustainable Energy, vol. 2, no. 2, pp. 109-121, Apr. 2011.

[19]. J. Hee-Yeol, A. R. Kim, K. Jae-Ho, P. Minwon, Y. In-Keun, K. Seok-Ho, S. Kideok, K. Hae-Jong, S. Ki-Chul, T. Asao, and J. Tamura, "A study on the operating characteristics of SMES for the dispersed power generation system," IEEE Trans. Appl. Supercond., vol. 19, no. 3, pp. 2028-2031, Jun. 2009.

[20]. S. S. Chen, L. Wang, W. J. Lee, and Z. Chen, "Power flow control and damping enhancement of a large wind farm using a superconducting magnetic energy storage unit," IET Renew. Power Gener., vol. 3, no. 1, pp. 23-38, Mar. 2009.

[21]. M. H. Ali, P. Minwon, Y. In-Keun, T. Murata, and J. Tamura, "Improvement of wind-generator stability by fuzzy-logic-controlled SMES,” IEEE Trans. Ind. Appl., vol. 45, no. 3, pp. 1045-1051, May/Jun. 2009.

[22]. F. Zhou, G. Joos, C. Abbey, L. Jiao, and B. T. Ooi, "Use of large capacity SMES to improve the power quality and stability of wind farms," in Proc. IEEE Power Eng. Soc. Gen. Meeting, 2004, vol. 2, pp. 2025-2030.

[23]. M. R. I. Sheikh, S. M. Muyeen, R. Takahashi, T. Murata, and J. Tamura, "Minimization of fluctuations of output power and terminal voltage of wind generator by using STATCOM/SMES," in Proc. IEEE Bucharest PowerTech, 2009, pp. 1-6. 
[24]. T. Asao, R. Takahashi, T. Murata, J. Tamura, M. Kubo, A. Kuwayama, and T. Matsumoto, "Smoothing control of wind power generator output by superconducting magnetic energy storage system," in Proc. ICEMS, 2007, pp. 302-307.

[25]. J. Hee-yeol, P. Dae-Jin, S. Hyo-Ryong, P. Minwon, and Y. In-Keun, "Power quality enhancement of grid-connected wind power generation system by SMES,” in Proc. IEEE/PES PSCE, 2009, pp. 1-6.

[26]. W. Li, C. Shiang-Shong, L. Wei-Jen, and C. Zhe, "Design of a damping controller for a SMES unit to suppress tie-line active-power fluctuations of a large-scale wind farm," in Proc. IEEE/PES PSCE, 2009, pp. 1-7.

[27]. P. F. Ribeiro, B. K. Johnson, M. L. Crow, A. Arsoy, and Y. Liu, "Energy storage systems for advanced power applications," Proc. IEEE, vol. 89, no. 12, pp. 1744-1756, Dec. 2001.

[28]. S. C. Smith, P. K. Sen, and B. Kroposki, "Advancement of energy storage devices and applications in electrical power system," in Proc. IEEE Power Energy Soc. Gen. Meeting — Convers. Del. Elect. Energy 21st Century, 2008, pp. 1-8.

[29]. H. Chen, T. N. Cong, W. Yang, C. Tan, Y. Li, and Y. Ding, "Progress in electrical energy storage system: A critical review," Progr. Natural Sci., vol. 19, no. 3, pp. 291-312, Mar. 2009.

[30]. E. Ancha, V. G. Agelidis, O. Anaya-Lara, and T. J. E. Miller, Power Electronic Control in Electrical Systems. Oxford, U.K.: Newnes, 2002.

[31]. I. D. Hassan, R. M. Bucci, and K. T. Swe, “400 MW SMES power conditioning system development and simulation,” IEEE Trans. Power Electron., vol. 8, no. 3, pp. 237-249, Jul. 1993.

[32]. A. R. Kim, S. Hyo-Ryong, K. Gyeong-Hun, P. Minwon, Y. In-Keun, Y. Otsuki, J. Tamura, K. Seok-Ho, S. Kideok, and S. Ki-Chul, "Operating characteristic analysis of HTS SMES for frequency stabilization of dispersed power generation system," IEEE Trans. Appl. Supercond., vol. 20, no. 3, pp. 1334-1338, Jun. 2010.

[33]. S. Jing, T. Yuejin, X. Yajun, R. Li, and L. Jingdong, "SMES based excitation system for doubly-fed induction generator in wind power application," IEEE Trans. Appl. Supercond., vol. 21, no. 3, pp. 1105-1108, Jun. 2011.

[34]. M. G. Molina and P. E. Mercado, "Power flow stabilization and control of microgrid with wind generation by superconducting magnetic energy storage," IEEE Trans. Power Electron., vol. 26, no. 3, pp. 910-922, Mar. 2011.

[35]. K. Bong-Hwan, K. Tae-Woo, and Y. Jang-Hyoun, "A novel SVM-based hysteresis current controller," IEEE Trans. Power Electron., vol. 13, no. 2, pp. 297-307, Mar. 1998.

[36]. M. Milosevic, Hysteresis Current Control in Three-Phase Voltage Source Inverter, Feb. 19, 2011. [Online]. Available: http://www.eeh.ee.ethz.ch/ uploads/tx ethpublications/milosevic hysteresis.pdf

[37]. L. Malesani and P. Tenti, "A novel hysteresis control method for current-controlled voltage-source PWM inverters with constant modulation frequency," IEEE Trans. Ind. Appl., vol. 26, no. 1, pp. 88-92, Jan./Feb. 1990.

[38]. H. Li and M. M. Gupta, Fuzzy Logic and Inteligent System. Norwell, MA: Kluwer, 1995.

[39]. V. Ahkmatov, "Analysis of dynamic behaviour of power systems with large amount of wind power," Ph.D. thesis, Tech. Univ. Denmark, Lyngby, Denmark, Feb. 25, 2011.

[40]. J. Rogers, H. Boenig, R. Schermer, and J. Hauer, "Operation of the $30 \mathrm{MJ}$ superconducting magnetic energy storage system in the Bonneville Power Administration electrical grid,” IEEE Trans. Magn., vol. MAG-21, no. 2, pp. 752-755, Mar. 1985.

[41]. M. G. Rabbani, J. B. X. Devotta, and S. Elangovan, "Application of simultaneous active and reactive power modulation of SMES unit under unequal \&alpha;-mode for power system stabilization,” IEEE Trans. Power Syst., vol. 14, no. 2, pp. 547-552, May 1999.

\section{VI.BIOGRAPHIES}

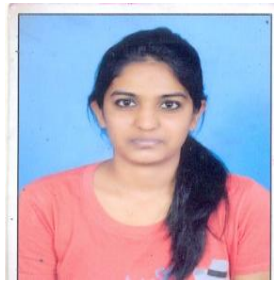

Ayesha Sarosh studying B.Tech Final Year in Gitam University, Hyderabad. She was very eager about the applications of Power Electronics, having very much Interest to do researches in the area of Power Electronics applications in Power systems.

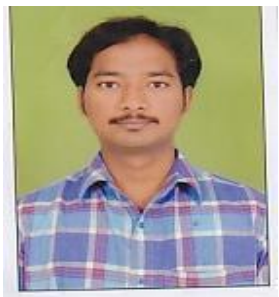

M.Sudhakar graduated in EEE from Kakatiya University in 2007. He received M.Tech degree in the stream of Power Electronics from Jawaharlal Nehru Technological University, Hyderabad in the year 2011. Presently working as Assistant Professor in Khammam Institute of Technology \& Sciences.

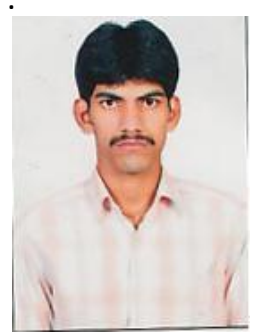

M.Shankar graduated in EEE from JNTH University in 2007. He received M.Tech degree in the stream of Control Systems from Jawaharlal Nehru Technological University, Hyderabadinthe year2011. Presently working as Assistant Professor in Khammam Institute of Technology \& Sciences. 